\title{
Effect of gene environment interactions on lung function and cardiovascular disease in COPD
}

This article was published in the following Dove Press journal:

International Journal of Chronic Obstructive Pulmonary Disease

9 May 2011

Number of times this article has been viewed

\author{
Tillie-Louise Hackett ${ }^{1,2, *}$ \\ Dorota Stefanowicz,** \\ Farzian Aminuddin' \\ Don D Sin' \\ John E Connett ${ }^{3}$ \\ Nicholas R Anthonisen ${ }^{4}$ \\ Peter D Paré \\ Andrew J Sandford'
}

'University of British Columbia, James Hogg Research Laboratories, St Paul's Hospital, Division of Respirology, Department of Medicine, ${ }^{2}$ Department of Anesthesiology, Pharmacology, and Therapeutics, University of British Columbia, Vancouver, BC, Canada; ${ }^{3}$ School of Public Health, University of Minnesota, Minneapolis, MN, USA ${ }^{4}$ Faculty of Medicine, University of Manitoba, Winnipeg, MB, Canada

*These authors contributed equally to this work
Correspondence: Andrew Sandford UBC James Hogg Research Centre at the Heart and Lung Institute, St Paul's Hospital, 108I Burrard Street, Vancouver, BC, Canada V6Z IY6

Tel +l 6048068346

Fax + I 604806835 |

Email andrew.sandford@hli.ubc.ca
Background: The objective of this study was to determine if gene-environment interactions between cigarette smoking and interleukin-6 (ILO), interferon- $\gamma($ IFNG), interleukin-1 $\beta$ (ILIB), or interleukin-1 receptor antagonist $(I L I R N)$ single nucleotide polymorphisms are associated with lung function decline and cardiovascular disease in chronic obstructive pulmonary disease (COPD).

Methods: Single nucleotide polymorphisms (SNPs) in IL6,IFNG, ILIB, and ILIRN were genotyped in the Lung Health Study and correlated with rate of decline of forced expiratory volume in 1 second $\left(\mathrm{FEV}_{1}\right)$ over 5 years, baseline $\mathrm{FEV}_{1}$, serum protein levels, cardiovascular disease, and interactions with smoking.

Results: The IL6 rs2069825 single nucleotide polymorphism was associated with the rate of decline of prebronchodilator $\mathrm{FEV}_{1}(P=0.049)$, and was found to have a significant interaction $(P=0.004)$ with mean number of cigarettes smoked per day. There was also a significant interaction of IFNG rs2069727 with smoking on prebronchodilator $(P=0.008)$ and postbronchodilator $(P=0.01) \mathrm{FEV}_{1}$. The IL6 polymorphism was also associated with cardiovascular disease in heterozygous individuals $(P=0.044)$, and was found to have a significant interaction with smoking $(P=0.024)$. None of the genetic variants were associated with their respective serum protein levels.

Conclusion: The results suggest interactions of IL6 rs2069825 and IFNG rs2069727 single nucleotide polymorphisms with cigarette smoking on measures of lung function. The IL6 rs2069825 single nucleotide polymorphism also interacted with smoking to affect the risk of cardiovascular disease in COPD patients.

Keywords: gene-environment interactions, interleukin-6, forced expiratory volume in one second, cardiovascular disease, chronic obstructive pulmonary disease

\section{Introduction}

Cigarette smoking is responsible for nearly five million deaths annually, with the leading cause of tobacco-related mortality being cardiovascular disease, followed by chronic obstructive pulmonary disease (COPD). ${ }^{1}$ While the adverse effects of cigarette smoking on lung health and "systemic" diseases are well established, the precise mechanism by which cigarette smoke mediates its systemic effects needs to be clarified. Due to the large variation in the adverse effects of cigarette smoke, it has been proposed that other factors, such as gene-environment interactions, may be important in promoting tobacco-related disease. ${ }^{2,3}$ COPD represents a clear example of gene-environment interactions because although cigarette smoking is the main environmental trigger for COPD in developed countries, considerable variation exists in disease outcomes, which are likely related to an individual's genetic load. 
Pulmonary inflammation is central to the development of COPD, characterized by increased numbers of neutrophils, macrophages, and lymphocytes, leading to the destruction of lung parenchyma, goblet cell hypertrophy, and tissue remodeling. In some patients, COPD is associated with systemic effects, which include cachexia, skeletal muscle wasting, and increased comorbidities, such as cardiovascular disease. ${ }^{4}$ These systemic effects may be caused or sustained by the enhanced systemic inflammation observed in some COPD patients.

Due to the complexity of the inflammatory mediators released by immune cells in response to smoking, multiple mediators have been suggested to be involved in the progression of COPD. We have previously demonstrated the association between interleukin-6 (ILG), interferon- $\gamma$ $(I F N G)$, interleukin-1 $\beta$ (ILIB), and interleukin-1 receptor antagonist $(I L 1 R N)$ polymorphisms and a rapid decline or baseline level of lung function in smokers. ${ }^{5-7}$ The Lung Health Study (LHS) is a multicenter community-based cohort of smokers with mild to moderate airflow limitation. ${ }^{8}$ Our previous studies utilized a subset of individuals from the LHS cohort to form a nested case-control study based on the extremes of distribution for the rate of decline in lung function and baseline lung function. ${ }^{5-7}$ Our rationale in this study was to investigate if gene $\times$ smoking interactions were associated with lung function decline in the entire LHS cohort. This approach would therefore allow us to estimate the effect of the identified polymorphisms and interactions with smoking on continuous measures of lung function, rather than dichotomous extremes, which the previous subset analyses were underpowered to perform. Our second aim was to determine whether the genetic variants and/or gene $\times$ smoking interactions were predictors of cardiovascular disease. We hypothesized that the link between COPD and mortality from cardiovascular disease is inflammation, through both local and systemic mechanisms.

\section{Methods}

\section{LHS participants}

The details of the LHS cohort have previously been published. ${ }^{8}$ Briefly, 5887 subjects who were cigarette smokers, aged 35-60 years, with mild to moderate airflow obstruction were recruited into the LHS cohort. Airflow obstruction was defined by a forced expiratory volume in one second $\left(\mathrm{FEV}_{1}\right)$ to forced vital capacity (FVC) ratio of $\leq 0.70$ and $\mathrm{FEV}_{1} 55 \%-90 \%$ of predicted. Lung function measurements were performed annually over the 5 years of the study using standardized spirometry, with quality control in accordance with the American Thoracic Society guidelines. ${ }^{9,10}$ During the follow-up phase of the study, the vital status of the participants was captured every 6 months. An independent mortality and morbidity committee reviewed death certificates, autopsy reports, and relevant hospital records to assign the causes of death for all participants who died during the study and confirmed data by linkage with the US National Death Index. ${ }^{11}$

On recruitment into the LHS cohort, each individual's smoking history was recorded in pack-years. At each subsequent annual visit, the smoking status of each participant was ascertained based on self-reporting and was objectively verified by determining cotinine levels in saliva samples and/ or carbon monoxide concentrations in expired air (Minico, Catalyst Research or EC50, Vitalograph). Participants were categorized as continued smokers or sustained quitters based on self-reporting and a validated biochemical measurement at all five follow-up visits. ${ }^{8}$

Individuals who had a history of cancer (except carcinoma in situ or basal cell carcinoma of the skin), myocardial infarction (in the past 2 years), angina, heart failure, stroke (in the past 2 years), renal failure, insulin-requiring diabetes mellitus, cirrhosis or other serious liver disease, pulmonary embolism, disorders of the central nervous system, narrowangle glaucoma, or any other major diseases which could have compromised follow-up, were excluded from the cohort.

\section{Polymorphism selection and genotyping methods}

Four single nucleotide polymorphisms (SNPs) were selected because they showed significant associations with either rate of decline or baseline lung function in our previous nested case-control studies of the LHS cohort. ${ }^{5-7}$ In addition, the respective proteins have previously been implicated in the pathogenesis of cardiovascular disease. ${ }^{12-17}$ Genotyping was performed using the TaqMan method (Applied Biosystems, Foster City, CA).

\section{Serum IL6, ILI $\beta$, ILIRN, and IFNG concentrations}

At the fifth annual visit, DNA and serum was isolated using venipuncture. The serum samples were stored at $-70^{\circ} \mathrm{C}$ and used to measure the concentrations of $I L 6, I L 1 \beta, I L I R N$, and IFNG using a highly sensitive chemiluminescent multiplexed sandwich immunoassay (SearchLight Proteome Array System, Rockford, IL). 


\section{Statistical analysis}

Hardy-Weinberg equilibrium was assessed using $\chi^{2}$ goodness-of-fit tests, and linkage disequilibrium estimations were performed using the CubeX cubic exact solutions program. ${ }^{18}$ Multivariate linear regressions for prebronchodilator and postbronchodilator rate of decline were performed to test for associations with each SNP. The confounding factors included for these analyses were age, body mass index, smoking status (continuous versus noncontinuous), and mean number of cigarettes smoked per day during the LHS follow-up period.

Multivariate linear regressions for baseline $\mathrm{FEV}_{1} \%$ predicted were performed to test for associations with each SNP. Confounding factors included for analyses of baseline lung function were age, body mass index, and pack-years of smoking. Pack-years of smoking was used as the covariate because this smoking measure was thought to be the most representative of patient smoking history prior to the start of the study.

Multivariate logistic regressions were used to test for the association of each SNP with cardiovascular disease and fatal cardiovascular disease.

Multivariate linear regressions were also performed to test for association of each SNP with logarithmically transformed serum levels of their respective proteins, with age, body mass index, and pack-years of smoking included as covariates.

Rate of decline in lung function was determined by the difference between lung function at the start and end of the study divided by the number of years between the two measurements. Gene $\times$ smoking interactions were tested in the entire LHS cohort by adding a multiplicative term to the regression models.

The single locus analyses described above were performed using the JMP statistical package (SAS Institute Inc, Cary, NC). Haplotype analysis was done using the SimHap package. ${ }^{19}$ If we were to apply a Bonferroni correction for the total number of 29 comparisons conducted in this study, there would be no association that would survive this stringent level of correction. Because many of the phenotypes and the $I L 1 B$ and $I L 1 R N$ SNPs tested were significantly associated, we used a matrix spectral decomposition approach to estimate the effective number of independent phenotypes and genotypes. ${ }^{20}$ Using the matrix spectral decomposition approach, the total effective number of variables $\left(\mathrm{V}_{\text {eff }}\right)$ tested for $I L 6, I F N G, I L 1 B$, and $I L 1 R N$ was 8.15, 7.25, 9, and 9, respectively. The significance threshold required to keep the Type I error rate at $5 \%\left(0.05 / \mathrm{V}_{\text {eff }}\right)$ for $I L 6, I F N G, I L 1 B$, and $I L 1 R N$ was $6.137 \times 10^{-3}, 6.894 \times 10^{-3}, 5.555 \times 10^{-3}$, and $5.555 \times 10^{-3}$, respectively, for each gene.

\section{Results}

\section{Characteristics of study participants}

Of the 5887 LHS participants, 4189 had DNA and complete phenotypic data available. Of those, 4036 (96\%) were of European descent and were utilized in the subsequent analyses because we had insufficient power to study the other ethnic groups. The total cohort $(n=4036)$ was used to investigate gene $\times$ smoking interactions on lung function, the effects of polymorphisms on serum levels of their respective proteins, and the influence of genetic variants on cardiovascular disease. The subset of LHS participants $(n=2523)$ that had not been previously included in genetic studies of these polymorphisms was used to investigate associations with lung function measures. The demographic characteristics of the LHS participants are shown in Table 1.

Table I Distribution of demographic characteristics for participants in the Lung Health Study

\begin{tabular}{|c|c|c|}
\hline & Total cohort & Subset $^{\mathrm{a}}$ \\
\hline & $(\mathrm{N}=4036)$ & $(\mathbf{N}=\mathbf{2 5 2 3})$ \\
\hline Gender (F/M) & 1479/2557 & $925 / 1598$ \\
\hline Age (years) & $48.5 I(6.74)$ & $48.54(6.69)$ \\
\hline Smoking history (pack years ${ }^{b}$ ) & $40.26(18.29)$ & $40.36(18.12)$ \\
\hline Mean cigarettes/day & $15.09(13.55)$ & $13.97(13.69)$ \\
\hline \multicolumn{3}{|c|}{ Smoking status during 5-year follow-up ${ }^{d}$} \\
\hline Continuing smokers & 2177 & 1169 \\
\hline Intermittent quitters & 1148 & 833 \\
\hline Sustained quitters & 711 & 521 \\
\hline BMI $\left(\mathrm{kg} / \mathrm{m}^{2}\right)$ & $25.52(3.83)$ & $25.56(3.84)$ \\
\hline Baseline $\mathrm{FEV}_{1}(\% \text { predicted pre-BD })^{\mathrm{e}}$ & $75.41(8.87)$ & $76.18(6.57)$ \\
\hline Baseline $\mathrm{FEV}_{1}(\% \text { predicted post-BD })^{f}$ & $78.55(9.20)$ & $79.16(5.88)$ \\
\hline$\Delta \mathrm{FEV}_{1} /$ year $\left(\%\right.$ predicted pre-BD) ${ }^{\mathrm{g}}$ & $-0.83(1.67)$ & $-0.72(1.37)$ \\
\hline$\Delta \mathrm{FEV}_{1} /$ year $(\% \text { predicted post-BD })^{\mathrm{h}}$ & $-0.64(1.57)$ & $-0.51(1.36)$ \\
\hline Median (IQR) IL6 (pg/mL) & $2.6(1.8-4.3)$ & NA \\
\hline Median (IQR) IFN $\gamma(\mathrm{pg} / \mathrm{mL})$ & $6.1(3.4-14.2)$ & NA \\
\hline Median (IQR) ILIRN (pg/mL) & $138(96-198)$ & NA \\
\hline Median (IQR) ILI $\beta(p g / m L)$ & $1.27(0.79-2.44)$ & NA \\
\hline Cardiovascular disease death (yes/no) & $71 / 3965$ & NA \\
\hline Cardiovascular disease (yes/no) & $705 / 3331$ & NA \\
\hline
\end{tabular}

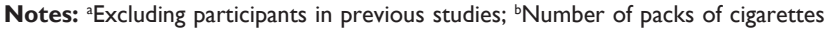
smoked per day times number of years smoking; 'Number of cigarettes smoked per day during 5-year follow-up; ${ }^{\circ}$ Continuing smokers: participants who reported smoking at each annual visit. Sustained quitters: participants who were validated by salivary cotinine or exhaled carbon monoxide levels as abstinent at every annual visit. Intermittent quitters: participants who were not sustained quitters or continuing smokers; 'Lung function at the start of the LHS measured as FEV, \% predicted pre-bronchodilator; 'Lung function at the start of the LHS measured as $\mathrm{FEV}, \%$ predicted post-bronchodilator; ${ }^{8}$ Change in lung function per year over a

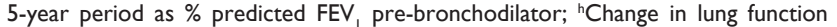
per year over a 5 -year period as \% predicted FEV, post-bronchodilator. Values are means $\pm S D$ for continuous data unless otherwise stated.

Abbreviations: $\mathrm{BD}$, bronchodilator; $\mathrm{BMI}$, body mass index; $\mathrm{FEV}_{1}$, forced expiratory volume in I second; IL6, interleukin-6; IFN $\gamma$, interferon gamma; ILIRN, interleukin I receptor antagonist; ILI $\beta$, interleukin-I $\beta$; IQR, interquartile range. 


\section{Polymorphism genotyping assays, linkage disequilibrium, and Hardy-Weinberg equilibrium}

In our previous study of $I L 1 B$ and $I L I R N$ polymorphisms, we genotyped a variable number of tandem repeats in intron 2 of the $I L 1 R N$ gene. ${ }^{7}$ In order to facilitate rapid genotyping of the large number of samples in this study, we utilized a SNP (rs419598) that was reported to be in high linkage disequilibrium with the tandem repeat polymorphism. ${ }^{21}$ We confirmed this association in a sample of 571 LHS participants for whom we had genotypic information for both polymorphisms. The linkage disequilibrium statistic between the tandem repeat (considering alleles A1 and A2) and rs419598 in these individuals was $\mathrm{r}^{2}=0.97$.

We genotyped the LHS participants for four polymorphisms, ie, rs2069825 in IL6, rs2069727 in IFNG, rs16944 in $I L 1 B$, and rs419598 in $I L 1 R N$. In the total of 4032 individuals, genotyping success rates were in the range of $91.8 \%-96.2 \%$. The frequencies of the SNP alleles and genotypes are listed in Table 2. All SNPs were in Hardy-Weinberg equilibrium in all groups, except for IL6 rs2069825, for which there was a slight excess of heterozygotes $(P=0.02)$.

\section{Analysis of rate of decline and baseline FEV}

We analyzed each polymorphism for association with rate of decline of prebronchodilator and postbronchodilator $\mathrm{FEV}_{1}$ in the LHS participants not previously studied for these variants. In contrast with our previous studies, ${ }^{5,6}$ there was no association of any polymorphism with the rate of decline of lung function (Table 3). Similarly, there was no association of the polymorphisms with measures of baseline lung function in the same subset of individuals (Table 3). However, when we analyzed the entire LHS cohort $(P=0.0486)$ and the original subset of patients $(P=0.0063)$ we did find a significant effect of the IL6 rs2069825 SNP on the rate of decline of prebronchodilator $\mathrm{FEV}_{1}$ (Table 4).
We had previously found a significant association of $I L I B$ and ILIRN haplotypes with rate of decline of lung function. ${ }^{7}$ Therefore, we tested haplotypes of the rs 16944 and rs419598 polymorphisms in the LHS cohort not previously tested. Contrary to our previous results, none of the haplotypes were associated with the rate of decline of lung function or with baseline lung function. When we analyzed the entire LHS cohort, we also found no significant associations except with the original subset analysis (data not shown).

\section{Analysis of gene $\times$ smoking interactions}

We investigated gene $\times$ smoking interactions in the entire LHS cohort. The data in Table 4 suggested a recessive effect of the IL6 rs2069825 SNP and therefore interactions of this polymorphism were explored in a recessive model. We found a significant interaction $(P=0.0044)$ of the IL6 rs2069825 SNP with mean number of cigarettes smoked per day on rate of decline of prebronchodilator $\mathrm{FEV}_{1}$ (Table 5) which remained significant after corrections for multiple comparisons by gene $(P=0.0359)$. This interaction is illustrated in Figure 1, which shows a faster rate of decline in individuals with the IL6 rs2069825 [-/-] genotype. There was also a significant overall interaction of IFNG rs2069727 with smoking on prebronchodilator $(P=0.0098)$ and postbronchodilator $(P=0.0077) \mathrm{FEV}_{1}$ (Table 5). There were no significant gene $\times$ smoking interactions on lung function parameters with the other polymorphisms studied.

\section{Analysis of serum protein levels}

We determined whether each of the four polymorphisms was associated with the serum level of its respective protein. However, none of the genetic variants was significantly associated with the protein levels of IL6, IL1 $\beta$, IL1RN, or IFN $\gamma$ measured in peripheral blood $(P=0.176-0.599)$.

Table 2 Frequency of SNP alleles and genotypes in the total cohort $(n=4036)$

\begin{tabular}{|c|c|c|c|c|c|c|c|c|}
\hline \multirow[t]{2}{*}{ Gene } & \multirow[t]{2}{*}{ SNP } & \multirow[t]{2}{*}{ Alleles $^{\mathbf{a}}$} & \multirow[t]{2}{*}{ Chromosomal location ${ }^{b}$} & \multirow[t]{2}{*}{ Position in gene } & \multirow[t]{2}{*}{$\begin{array}{l}\text { Minor allele } \\
\text { frequency (\%) }\end{array}$} & \multicolumn{3}{|c|}{$\begin{array}{l}\text { Genotype } \\
\text { frequency (\%) }\end{array}$} \\
\hline & & & & & & AA & AB & BB \\
\hline IL6 & rs2069825 & $\mathrm{CT} /-$ & $7: 2276534 I-22765342$ & Promoter & 39 & 38 & 46 & 16 \\
\hline IFNG & rs2069727 & $\mathrm{A} / \mathrm{G}$ & 12: 68548223 & $3^{\prime}$ region & 47 & 29 & 49 & 22 \\
\hline ILIRN & rs419598 & $\mathrm{T} / \mathrm{C}$ & 2: II 3887207 & Exon 3 & 27 & 53 & 39 & 8 \\
\hline ILIB & rsI6944 & $\mathrm{C} / \mathrm{T}$ & 2: II 3594867 & Promoter & 33 & 45 & 44 & II \\
\hline
\end{tabular}

Notes: ${ }^{a}$ The first allele is the major allele, the second is the minor allele; ${ }^{\mathrm{b}} \mathrm{Chromosome:} \mathrm{base} \mathrm{position} \mathrm{(NCBI} \mathrm{Build} \mathrm{37.I).}$ 
Table 3 Analysis of rate of decline and baseline of FEV, in the LHS subset not previously studied

\begin{tabular}{|c|c|c|c|c|c|}
\hline Gene & Polymorphism & Genotype $^{a}$ & $\beta$ (\% predicted/year) & SE & $P$ value \\
\hline \multicolumn{6}{|c|}{ Rate of decline of pre-bronchodilator FEV, } \\
\hline \multirow[t]{3}{*}{ IL6 } & rs2069825 & $\mathrm{CT} / \mathrm{CT}$ & - & - & - \\
\hline & & $-/ C T$ & -0.0404 & 0.0369 & 0.2733 \\
\hline & & $-1-$ & 0.0378 & 0.0475 & 0.4267 \\
\hline \multirow[t]{3}{*}{ IFNG } & rs2069727 & $\mathrm{A} / \mathrm{A}$ & - & - & - \\
\hline & & $A / G$ & 0.0178 & 0.0354 & 0.6142 \\
\hline & & $\mathrm{G} / \mathrm{G}$ & -0.0078 & 0.0425 & 0.8540 \\
\hline \multirow[t]{3}{*}{ ILIRN } & rs4I9598 & $\mathrm{T} / \mathrm{T}$ & - & - & - \\
\hline & & $\mathrm{C} / \mathrm{T}$ & 0.0351 & 0.0438 & 0.4228 \\
\hline & & $\mathrm{C} / \mathrm{C}$ & -0.0462 & 0.0644 & 0.4728 \\
\hline \multirow[t]{3}{*}{ ILIB } & rsI6944 & $\mathrm{C} / \mathrm{C}$ & - & - & - \\
\hline & & $\mathrm{C} / \mathrm{T}$ & 0.0333 & 0.0387 & 0.3897 \\
\hline & & $T / T$ & -0.0477 & 0.0535 & 0.3729 \\
\hline \multicolumn{6}{|c|}{ Rate of decline of post-bronchodilator FEV } \\
\hline \multirow[t]{3}{*}{ IL6 } & rs2069825 & $\mathrm{CT} / \mathrm{CT}$ & - & - & - \\
\hline & & $-/ \mathrm{CT}$ & -0.0632 & 0.0358 & 0.0776 \\
\hline & & $-1-$ & 0.0218 & 0.0462 & 0.6366 \\
\hline \multirow[t]{3}{*}{ IFNG } & rs2069727 & $\mathrm{A} / \mathrm{A}$ & - & - & - \\
\hline & & $A / G$ & 0.0150 & 0.0343 & 0.6605 \\
\hline & & $\mathrm{G} / \mathrm{G}$ & -0.0198 & 0.0412 & 0.6306 \\
\hline \multirow[t]{3}{*}{ ILIRN } & rs4l9598 & $\mathrm{T} / \mathrm{T}$ & - & - & - \\
\hline & & $\mathrm{C} / \mathrm{T}$ & -0.0239 & 0.0425 & 0.5736 \\
\hline & & $\mathrm{C} / \mathrm{C}$ & 0.0095 & 0.0626 & 0.8787 \\
\hline \multirow[t]{3}{*}{ ILIB } & rsI6944 & $\mathrm{C} / \mathrm{C}$ & - & - & - \\
\hline & & $\mathrm{C} / \mathrm{T}$ & 0.0394 & 0.0377 & 0.2951 \\
\hline & & $T / T$ & -0.0408 & 0.0520 & 0.4321 \\
\hline \multicolumn{6}{|c|}{ Baseline level of pre-bronchodilator FEV, } \\
\hline \multirow[t]{3}{*}{ IL6 } & rs2069825 & CT/CT & - & - & - \\
\hline & & $-/ C T$ & -0.0300 & 0.1853 & 0.8712 \\
\hline & & $-1-$ & -0.2074 & 0.2390 & 0.3856 \\
\hline \multirow[t]{3}{*}{ IFNG } & rs2069727 & $\mathrm{A} / \mathrm{A}$ & - & - & - \\
\hline & & $\mathrm{A} / \mathrm{G}$ & -0.1192 & 0.1794 & 0.5064 \\
\hline & & $\mathrm{G} / \mathrm{G}$ & 0.2640 & 0.2154 & 0.2205 \\
\hline \multirow[t]{3}{*}{ ILIRN } & rs4l9598 & $\mathrm{T} / \mathrm{T}$ & - & - & - \\
\hline & & $\mathrm{C} / \mathrm{T}$ & -0.3209 & 0.2217 & 0.1478 \\
\hline & & $\mathrm{C} / \mathrm{C}$ & 0.3707 & 0.3264 & 0.2562 \\
\hline \multirow[t]{3}{*}{ ILIB } & rsI6944 & $\mathrm{C} / \mathrm{C}$ & - & - & - \\
\hline & & $\mathrm{C} / \mathrm{T}$ & -0.1483 & 0.1958 & 0.4487 \\
\hline & & $T / T$ & 0.0501 & 0.2702 & 0.8528 \\
\hline \multicolumn{6}{|c|}{ Baseline level of post-bronchodilator FEV, } \\
\hline \multirow[t]{3}{*}{ IL6 } & rs2069825 & $\mathrm{CT} / \mathrm{CT}$ & - & - & - \\
\hline & & $-/ C T$ & -0.0262 & 0.1659 & 0.8747 \\
\hline & & $-1-$ & -0.2546 & 0.2139 & 0.2342 \\
\hline \multirow[t]{3}{*}{ IFNG } & rs2069727 & $\mathrm{A} / \mathrm{A}$ & - & - & - \\
\hline & & $A / G$ & -0.1650 & 0.1606 & 0.3043 \\
\hline & & $\mathrm{G} / \mathrm{G}$ & 0.3989 & 0.1928 & 0.0386 \\
\hline \multirow[t]{3}{*}{ ILIRN } & rs4l9598 & $\mathrm{T} / \mathrm{T}$ & - & - & - \\
\hline & & $\mathrm{C} / \mathrm{T}$ & -0.2209 & 0.1980 & 0.2649 \\
\hline & & $\mathrm{C} / \mathrm{C}$ & 0.1958 & 0.2917 & 0.5021 \\
\hline \multirow[t]{3}{*}{$I L I B$} & rsl6944 & $\mathrm{C} / \mathrm{C}$ & - & - & - \\
\hline & & $\mathrm{C} / \mathrm{T}$ & -0.2444 & 0.1749 & 0.1625 \\
\hline & & $\mathrm{T} / \mathrm{T}$ & 0.0098 & 0.2415 & 0.9677 \\
\hline
\end{tabular}

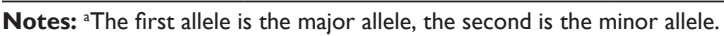

Abbreviations: FEVI, forced expiratory volume in I second; IFN $\gamma$, interferon gamma; ILIRN, interleukin I receptor antagonist; IL6, interleukin-6; ILI $\beta$, interleukin- I $\beta$. 
Table 4 Analysis of rate of decline of FEV, in the entire LHS cohort

\begin{tabular}{|c|c|c|c|c|c|}
\hline Gene & Polymorphism & Genotype $^{a}$ & $\beta$ (\% predicted/year) & SE & $P$ value \\
\hline \multicolumn{6}{|c|}{ Rate of decline of pre-bronchodilator FEV, } \\
\hline \multirow[t]{3}{*}{ IL6 } & rs2069825 & $\mathrm{CT} / \mathrm{CT}$ & - & - & - \\
\hline & & $-/ C T$ & 0.0582 & 0.0356 & 0.1020 \\
\hline & & $-1-$ & -0.1130 & 0.0460 & 0.0141 \\
\hline
\end{tabular}

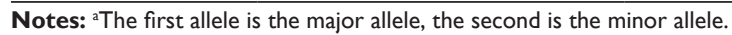

Abbreviation: FEVI, forced expiratory volume in I second; IL6, interleukin-6.

\section{Analysis of cardiovascular disease and fatal cardiovascular disease}

There was an association of the IL6 polymorphism with cardiovascular disease, although there was only an effect of the heterozygous genotype $(P=0.0446)$. There was no association of the IFNG polymorphism or ILIB-ILIRN haplotypes with either cardiovascular disease outcome. In addition, we found a significant gene $\times$ smoking interaction between cardiovascular disease and the IL6 polymorphism $(P=0.0239$, Table 6).

\section{Discussion}

We have investigated polymorphisms in the IL6, ILIRN, ILIB, and $I F N G$ genes which have previously been demonstrated as risk factors for accelerated decline in lung function or baseline lung function in COPD patients. Unlike our previous studies, which used nested case-control designs including patients within the extremes of distribution for lung function parameters, we only found an association for $I L 6$ with rate of decline in lung function for the entire LHS cohort. We found significant gene $\times$ smoking interactions between $I L 6$ and IFNG and the rate of decline in lung function and baseline $\mathrm{FEV}_{1}$, respectively. In addition, we also demonstrated a significant association between $I L 6$ and an $I L 6 \times$ smoking interaction for cardiovascular disease.

The current paradigm for the pathogenesis of COPD includes a local and systemic inflammatory response to environmental challenges, notably cigarette smoking, which ultimately results in airflow obstruction. In COPD patients, high levels of serum or sputum IL6 have been associated with impaired lung function, exacerbations, pulmonary infections, and skeletal muscle weakness. ${ }^{22-27}$ It has also been

Table 5 Analysis of gene $\times$ smoking interactions on lung function

\begin{tabular}{|c|c|c|c|}
\hline Term & $\beta$ & SE & $P$ value \\
\hline \multicolumn{4}{|l|}{ Rate of decline of pre-bronchodilator FEV, } \\
\hline Age & -0.0354 & 0.0038 & $<0.0001$ \\
\hline BMI & 0.0207 & 0.0066 & 0.0018 \\
\hline Smoking status [Continuous] ${ }^{a}$ & -0.2521 & 0.0340 & $<0.0001$ \\
\hline Mean cigarettes per day ${ }^{b}$ & -0.0274 & 0.0030 & $<0.000 \mathrm{I}$ \\
\hline IL6 rs2069825 [-/-] & -0.0851 & 0.0344 & 0.0136 \\
\hline IL6 rs2069825 [-/-] $\times$ Mean cigarettes per day & $-0.007 \mid$ & 0.0025 & 0.0044 \\
\hline \multicolumn{4}{|l|}{ Baseline level of pre-bronchodilator FEV, } \\
\hline Age & -0.1346 & 0.0229 & $<0.0001$ \\
\hline BMI & -0.0926 & 0.0371 & 0.0125 \\
\hline Smoking history (pack-years) & -0.0354 & 0.0088 & $<0.000$ I \\
\hline IFNG rs2069727 [A/G] & $0.284 I$ & 0.1891 & 0.1331 \\
\hline IFNG rs2069727 [G/G] & -0.3918 & 0.2280 & 0.0858 \\
\hline IFNG rs2069727 [A/G] × Smoking history & -0.0316 & 0.0126 & 0.0023 \\
\hline IFNG rs2069727 [G/G]× Smoking history & 0.0207 & 0.0158 & 0.0996 \\
\hline \multicolumn{4}{|l|}{ Baseline level of post-bronchodilator FEV, } \\
\hline Age & -0.2151 & 0.0236 & $<0.0001$ \\
\hline BMI & -0.0142 & 0.0382 & 0.7102 \\
\hline Smoking history (pack-years) & -0.0445 & 0.0091 & $<0.0001$ \\
\hline IFNG rs2069727 [A/G] & 0.3225 & 0.1947 & 0.0977 \\
\hline IFNG rs2069727 [G/G] & -0.4193 & 0.2347 & 0.0742 \\
\hline IFNG rs2069727 [A/G] × Smoking history & -0.0326 & 0.0107 & 0.0023 \\
\hline IFNG rs2069727 [G/G] × Smoking history & 0.0279 & 0.0129 & 0.0310 \\
\hline
\end{tabular}

Notes: ${ }^{2}$ Number of packs of cigarettes smoked per day times number of years smoking; ${ }^{\circ}$ Number of cigarettes smoked per day during 5-year follow-up. Abbreviations: BMI, body mass index; FEVI, forced expiratory volume in I second; IL6, interleukin-6; IFN $\gamma$, interferon gamma. 


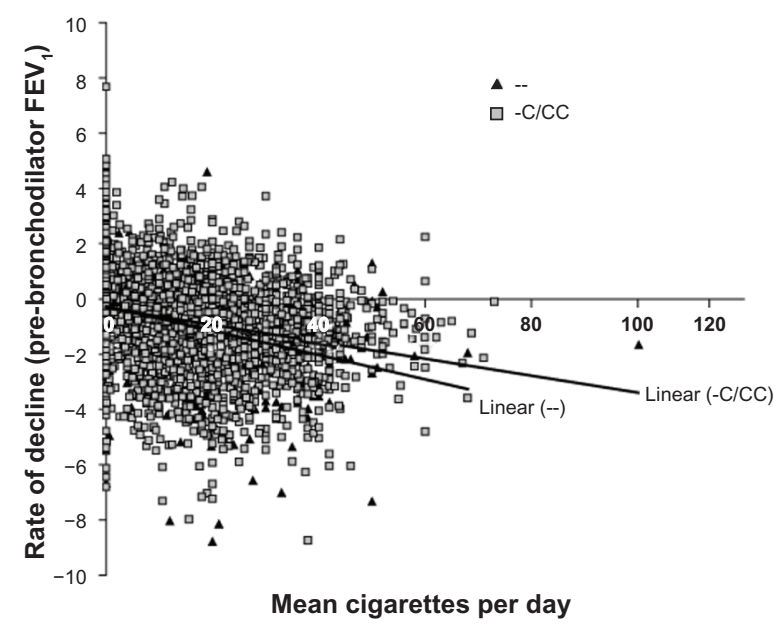

Figure I IL6 rs2069825 [-/-] genotype and rate of decline in lung function. Individuals in the Lung Health Study cohort were genotyped for the IL6 rs2069825 single nucleotide polymorphism. Their genotype was plotted against mean cigarettes per day ( $x$ axis) and rate of decline (prebronchodilator FEV, [y axis]). The slopes demonstrate a faster decline in individuals with a $[-/-]$ genotype (triangles) compared with individuals with the heterozygote $[-/ C]$ or homozygote $[C / C]$ genotypes (squares).

demonstrated that overexpression of IL6 in the adult murine lung results in airway inflammation and emphysema-like airspace enlargement. ${ }^{28}$ In this study, we found the IL6 SNP rs2069825 deletion allele was associated with rate of decline of prebronchodilator $\mathrm{FEV}_{1}$ in the entire LHS cohort. In a previous independent case-control sample study, associations of IL6 SNPs with COPD susceptibility were also found. In particular, these IL6 SNP were in high linkage disequilibrium with the IL6 SNP rs2069825 genotyped in the present study. ${ }^{5}$ IL6 haplotypes, including rs2069825, have been previously associated with COPD in an independent study of a Caucasian population. ${ }^{29}$ Furthermore, IL6 haplotypes have been found to be associated with COPD defined by lung function in a Spanish population. ${ }^{30}$ In contrast, a much

Table 6 Analysis of gene $\times$ smoking interactions on cardiovascular disease

\begin{tabular}{|c|c|c|c|}
\hline Term & $\beta$ & SE & $P$ value \\
\hline Gender [Male] & -0.3537 & 0.0524 & $<0.0001$ \\
\hline Age & -0.0762 & 0.0074 & $<0.0001$ \\
\hline BMI & -0.0330 & 0.0122 & 0.0069 \\
\hline Mean cigarettes per day ${ }^{a}$ & -0.0001 & 0.0036 & 0.9664 \\
\hline Diastolic blood pressure at year 5 & 0.0261 & 0.0065 & $<0.0001$ \\
\hline Systolic blood pressure at year 5 & -0.0261 & 0.0039 & $<0.0001$ \\
\hline IL6 rs2069825 [-/CT] & 0.1253 & 0.0624 & 0.0446 \\
\hline IL6 rs2069825 [-/-] & -0.0475 & 0.0792 & 0.5489 \\
\hline $\begin{array}{l}\text { IL6 rs2069825 }[-/ C T] \times \text { mean } \\
\text { cigarettes per day }\end{array}$ & -0.0101 & 0.0045 & 0.0239 \\
\hline $\begin{array}{l}\text { IL6 rs2069825 }[-I-] \times \text { mean } \\
\text { cigarettes per day }\end{array}$ & 0.0010 & 0.0058 & 0.0873 \\
\hline
\end{tabular}

Notes: ${ }^{N}$ Number of cigarettes smoked per day during 5-year follow-up. Abbreviations: BMI, body mass index; IL6, interleukin-6. smaller study has previously reported no association of an IL6 SNP (rs 1800795) with COPD. ${ }^{31}$ The rs 1800795 polymorphism is in high linkage disequilibrium $\left(\mathrm{r}^{2}=0.9\right)$ with the IL6 rs2069825 SNP investigated in this study. Because we believe that the associations found in well-powered cohorts are not likely to represent false positive results, together these studies indicate an association of IL6 SNPs with COPD. In contrast with our previous study in which we analyzed the association of the IL6 rs2069825 SNP with individuals not defined within the extremes of decline of lung function, we found no significant effect. However, when we analyzed the entire LHS cohort and the original subset of patients for rate of decline in prebronchodilator $\mathrm{FEV}_{1}$, we did confirm the findings of our previous study. ${ }^{5}$ Our finding of an ILG rs2069825 interaction with level of smoking indicates that other factors are required for the effect of IL6 rs2069825 to manifest. Indeed, this is the first study to demonstrate a gene $\times$ environment interaction for $I L 6$ and smoking with a lung function parameter.

The number of IFN $\gamma$-expressing lymphocytes is elevated in smokers and COPD bronchial biopsies. ${ }^{32}$ Studies of IFN $\gamma$ knockout mice have also demonstrated an important role for IFN $\gamma$ in emphysema. ${ }^{33}$ The IFNG rs2069727 SNP was previously associated with baseline lung function in the LHS subset using the extremes of the distribution of lung function measurements. ${ }^{6}$ We also found a significant interaction with smoking history in our previous study. ${ }^{6}$ Therefore, the interaction of rs2069727 with pack-years of smoking in the total LHS cohort found in this study is consistent with these data. In support of the importance of $I F N G$, a different $I F N G$ polymorphism (rs2430561) was previously associated with COPD in a Macedonian population. ${ }^{34}$ For the $I L 1 R N$ rs 419598 and IL1B rs16944 polymorphisms, we found no associations with rate of decline or baseline $\mathrm{FEV}_{1}$. We could confirm our findings of the previous association study for $I L 1 R N$ and $I L 1 B$ in the subset, but not the whole LHS cohort. This suggests that either the polymorphisms are only risk factors in the most severely affected individuals (those with very rapid decline in lung function), or the previous associations were false positive results.

It has long been recognized that smokers with COPD have high cardiovascular-related mortality. ${ }^{35,36}$ Indeed, decreased expiratory flow from the lung, which is the defining feature of COPD, increases the risk of ischemic heart disease, strokes, and sudden cardiac death by 2-3-fold, independent of other risk factors. ${ }^{37}$ In particular, this increased risk is thought to be especially relevant to patients with mild to moderate COPD, because in severe 
COPD patients the primary cause of death is usually respiratory disease..$^{11}$ The mechanisms of cardiovascular disease in COPD include hypoxia, systemic inflammation, and oxidative stress. ${ }^{38}$ Due to the poor correlations of circulating levels of cytokines such as tumor necrosis factor and interleukin-8 with sputum levels in COPD, the data suggest that systemic inflammation may not be a simple spillover effect from lung inflammation. ${ }^{39}$ Thus, intermediate factors may play an important role because smoking is associated with increased systemic levels of inflammatory mediators, including IL6, tumor necrosis factor, reactive oxygen species, and IFN $\gamma^{40,41}$ Although it is widely accepted that cigarette smoking induces systemic inflammation, which contributes to both the pathogenesis of COPD and cardiovascular disease morbidity and mortality, ${ }^{32,42}$ it is not known which inflammatory genes are important.

We found that the IL6 rs2069825 SNP was associated with cardiovascular disease. The minor allele of the IL6 promoter SNP, rs1800795 (-174G/C), has been previously associated with increased circulating IL6 levels, cardiovascular disease, and cardiovascular disease-related mortality in populations of older adults. ${ }^{43-46}$ However, IL6 gene variation was only weakly associated with serum IL6 levels and not with cardiovascular outcomes in the Cardiovascular Health Study. ${ }^{47}$ More recently, Carty et al studied several IL6 SNPs in the Cardiovascular Health Study, including the IL6 polymorphism, rs $1554606,{ }^{48}$ which is in moderate linkage disequilibrium $\left(r^{2}=0.49\right)$ with IL6 rs2069825, the SNPs used in our study. However, the study found no associations between the five IL6 SNPs investigated and cardiovascular outcomes. ${ }^{48}$ The differences in the findings for IL6 rs2069825 and cardiovascular disease outcome potentially reflects the cohorts studied. The Cardiovascular Health Study consisted of older patients (mean 72.6 years), of whom $59.5 \%$ were female and only $11.0 \%$ were current smokers ${ }^{49}$ in comparison with our cohort, which consisted of only current smokers (on enrollment) with COPD that were $36.6 \%$ female and younger (mean 48.51 years).

The systemic inflammatory response is characterized by stimulation of the hematopoietic system. Circulating cytokines, such as IL6, have been postulated to stimulate the bone marrow to release leukocytes and platelets involved in systemic inflammation. ${ }^{50}$ Several studies have shown increased levels of systemic IL6 in smokers compared with never-smokers. ${ }^{51,52}$ Furthermore, IL6 has been found to correlate significantly with fibrinogen and white blood cell counts, reflecting a major role for IL6 as an inducer of fibrinogen, ${ }^{53}$ which has been demonstrated to be an important marker in cardiovascular disease.$^{54}$ In addition, levels of IL 6 can be used to predict future cardiovascular disease. ${ }^{17,55}$ Indeed, in COPD, IL6 levels are increased, particularly during exacerbations, and IL6 levels parallel C-reactive protein levels. ${ }^{56}$

Our previous search for COPD susceptibility genes had focused on genes involved in the inflammatory response, but we had no intermediate phenotypes to test whether the significant associations we observed were acting through inflammatory pathways. The recent analysis of serum samples from the LHS participants offered the opportunity to use measurements of serum proteins and cytokines as powerful intermediate phenotypes. We examined the association of our identified SNPs with IL6, IFN $\gamma$, IL1 $\beta$, and IL1RN serum levels. We did not find any associations, and therefore we found no evidence that the associations we reported were mediated through an influence on the production of the serum cytokines measured. However, we did not measure cytokine levels within the lung, and therefore we could not test if the associations of IL6 rs2069825 with lung function are driven via local pulmonary expression.

There are several explanations for the lack of association between the SNPs studied and serum cytokine levels measured. Many serum proteins have been demonstrated to have marked diurnal variability, and the serum samples were not obtained at a specific time of day for all patients. Additionally, the serum half-life of cytokines such as IL6 is short. Another limitation is the lack of healthy nonsmoking control subjects, thus the relationship of these candidate genes to normal lung function decline with age and cardiovascular disease in a nonsmoking population is unknown.

Compared with previous studies, the strengths of this study include a larger sample size and good power. This sample size provides more than adequate power to detect common genetic risk variants, as shown in our previous power analyses..$^{57}$ There were several potential limitations to the study. First, false positive results could have been generated by population stratification. However, previous studies have suggested that US Caucasian populations are unlikely to contain sufficient stratification to cause widespread false positive results. ${ }^{58}$ One important difference with our previously identified associations between IL6, IFN $\gamma$, IL1 $\beta$, and IL1RN polymorphisms and rate of decline and baseline lung function is that these studies utilized a case-control analysis that compared individuals from the 
extremes of the distribution for rate of decline or baseline lung function. When we analyzed the entire LHS cohort, only the IL6 rs2069825 SNP remained significant. This could indicate that the IFNG rs2069727, ILIRN rs419598, and $I L 1 B$ rs 16944 polymorphisms previously identified are important only in individuals with severe airflow limitation and rapid decline in lung function over the course of their disease. There may also be increased power to detect genetic susceptibility loci using extremes of the distribution of a continuous variable. ${ }^{59}$ However, it is also possible that previous studies were underpowered and the results obtained were false positives.

In this study, we have made multiple comparisons and therefore most of the results would not be significant at the $5 \%$ level if a Bonferroni correction was made. On the other hand, only a limited number of SNPs were chosen based on a prior association with lung function measures in the LHS. Furthermore, the prebronchodilator and postbronchodilator measures of lung function utilized in this study are highly correlated. Only the association of the IL6 rs2069825 SNP with mean number of cigarettes smoked per day on rate of decline of prebronchodilator $\mathrm{FEV}_{1}$ was significant after correction for multiple comparisons. Thus, given the lack of formal significance for the other reported results, they should be regarded as hypothesis-generating.

In summary, we have demonstrated significant interactions of the IL6 rs2069825 and IFNG rs2069727 SNPs with cigarette smoking on lung function in a wellpowered cohort of exsmokers and current smokers. In addition, the IL6 rs2069825 SNP was also associated with cardiovascular disease. Because several large randomized clinical trials and population-based studies have demonstrated a substantial reduction in the risk of cardiovascular disease and loss of lung function following smoking cessation. ${ }^{60-62}$ We propose that individuals with the IL6 rs2069825 SNP would be at risk for the development of both COPD and cardiovascular disease, and could be targeted in future therapeutic strategies aimed at the IL6 pathway.

\section{Acknowledgments}

This work was supported by grants from the Canadian Institutes of Health Research and National Institutes of Health. The Lung Health Study was supported by the Division of Lung Diseases of the National Heart, Lung, and Blood Institute. TLH is a recipient of CIHR/Canadian Lung Association/GSK, CIHR IMPACT, and Michael Smith Foundation for Health Research post-doctoral fellowships. AS is the recipient of a Canada Research Chair in genetics and a Michael Smith Foundation for Health Research senior scholar award.

\section{Disclosure}

The authors have no conflicts of interest to report in this work.

\section{References}

1. Ezzati M, Lopez AD. Estimates of global mortality attributable to smoking in 2000. Lancet. 2003;362(9387):847-852.

2. Teo KK, Ounpuu S, Hawken S, et al. Tobacco use and risk of myocardial infarction in 52 countries in the INTERHEART study: A case-control study. Lancet. 2006;368(9536):647-658.

3. Garantziotis S, Schwartz DA. Ecogenomics of respiratory diseases of public health significance. Annu Rev Public Health. 2010;31:37-51.

4. Barnes PJ, Celli BR. Systemic manifestations and comorbidities of COPD. Eur Respir J. 2009;33(5):1165-1185.

5. He JQ, Foreman MG, Shumansky K, et al. Associations of IL6 polymorphisms with lung function decline and COPD. Thorax. 2009;64(8): 698-704.

6. He JQ, Burkett K, Connett JE, Anthonisen NR, Paré PD, Sandford AJ. Interferon gammapolymorphisms and their interaction with smoking are associated with lung function. Hum Genet. 2006;119(4):365-375.

7. Joos L, McIntyre L, Ruan J, et al. Association of IL-1beta and IL-1 receptor antagonist haplotypes with rate of decline in lung function in smokers. Thorax. 2001;56(11):863-866.

8. Anthonisen NR, Connett JE, Kiley JP, et al. Effects of smoking intervention and the use of an inhaled anticholinergic bronchodilator on the rate of decline of FEV1. The Lung Health Study. JAMA. 1994;272(19): 1497-1505.

9. Enright PL, Connett JE, Kanner RE, Johnson LR, Lee WW. Spirometry in the Lung Health Study. 1. Methods and quality control. Am Rev Respir Dis. 1991;143(6):1215-1223.

10. American Thoracic Society. Standardization of spirometry -1987 update. Statement of the American Thoracic Society. Am Rev Respir Dis. 1987;136(5):1285-1298.

11. Anthonisen NR, Skeans MA, Wise RA, et al. The effects of a smoking cessation intervention on 14.5-year mortality: A randomized clinical trial. Ann Intern Med. 2005;142(4):233-239.

12. Jha HC, Divya A, Prasad J, Mittal A. Plasma circulatory markers in male and female patients with coronary artery disease. Heart Lung. 2010;39(4):296-303.

13. Isoda K, Ohsuzu F. The effect of interleukin-1 receptor antagonist on arteries and cholesterol metabolism. JAtheroscler Thromb. 2006;13(1): 21-30.

14. Guillén I, Blanes M, Gómez-Lechón MJ, Castell JV. Cytokine signaling during myocardial infarction: Sequential appearance of IL-1 beta and IL-6. Am J Physiol. 1995;269(2 Pt 2):R229-R235.

15. Patti G, D'Ambrosio A, Mega S, et al. Early interleukin-1 receptor antagonist elevation in patients with acute myocardial infarction. J Am Coll Cardiol. 2004;43(1):35-38.

16. Miyao Y, Yasue H, Ogawa H, et al. Elevated plasma interleukin-6 levels in patients with acute myocardial infarction. Am Heart J. 1993;126(6): 1299-1304.

17. Cesari M, Penninx BW, Newman AB, et al. Inflammatory markers and cardiovascular disease (The Health, Aging and Body Composition [Health ABC] Study). Am J Cardiol. 2003;92(5):522-528.

18. Gaunt TR, Rodriguez S, Day IN. Cubic exact solutions for the estimation of pairwise haplotype frequencies: Implications for linkage disequilibrium analyses and a web tool 'CubeX'. BMC Bioinformatics. 2007;8:428.

19. Carter KW, McCaskie PA, Palmer LJ. SimHap GUI:An intuitive graphical user interface for genetic association analysis. BMC Bioinformatics. 2008;9:557. 
20. Nyholt DR. A simple correction for multiple testing for single-nucleotide polymorphisms in linkage disequilibrium with each other. Am J Hum Genet. 2004;74(4):765-769.

21. Clay FE, Tarlow JK, Cork MJ, Cox A, Nicklin MJ, Duff GW. Novel interleukin-1 receptor antagonist exon polymorphisms and their use in allele-specific mRNA assessment. Hum Genet. 1996;97(6):723-726.

22. De Torres JP, Pinto-Plata V, Casanova C, et al. C-reactive protein levels and survival in patients with moderate to very severe COPD. Chest. 2008;133(6):1336-1343.

23. Hurst JR, Perera WR, Wilkinson TM, Donaldson GC, Wedzicha JA. Systemic and upper and lower airway inflammation at exacerbation of chronic obstructive pulmonary disease. Am J Respir Crit Care Med. 2006;173(1):71-78.

24. Hurst JR, Donaldson GC, Perera WR. Use of plasma biomarkers at exacerbation of chronic obstructive pulmonary disease. Am J Respir Crit Care Med. 2006;174(8):867-874.

25. Wilkinson TM, Hurst JR, Perera WR, Wilks M, Donaldson GC, Wedzicha JA. Effect of interactions between lower airway bacterial and rhinoviral infection in exacerbations of COPD. Chest. 2006;129(2): 317-324.

26. Yende S, Waterer GW, Tolley EA, et al. Inflammatory markers are associated with ventilatory limitation and muscle dysfunction in obstructive lung disease in well functioning elderly subjects. Thorax. 2006;61(1): $10-16$

27. Broekhuizen R, Wouters EF, Creutzberg EC, Schols AM. Raised CRP levels mark metabolic and functional impairment in advanced COPD. Thorax. 2006;61(1):17-22.

28. Kuhn C 3rd, Homer RJ, Zhu Z, et al. Airway hyperresponsiveness and airway obstruction in transgenic mice. Morphologic correlates in mice overexpressing interleukin (IL)-11 and IL-6 in the lung. Am J Respir Cell Mol Biol. 2000;22(3):289-295.

29. Yanbaeva DG, Dentener MA, Spruit MA, et al. IL6 and CRP haplotypes are associated with COPD risk and systemic inflammation: A case-control study. BMC Med Genet. 2009;10:23.

30. Córdoba-Lanús E, de-Torres JP, López-Aguilar C, et al. Association of IL-6 gene polymorphisms and COPD in a Spanish population. Respir Med. 2008;102(12):1805-1811.

31. Seifart C, Dempfle A, Plagens A, et al. TNF-alpha-, TNF-beta-, IL-6-, and IL-10-promoter polymorphisms in patients with chronic obstructive pulmonary disease. Tissue Antigens. 2005;65(1):93-100.

32. Hogg JC. Pathophysiology of airflow limitation in chronic obstructive pulmonary disease. Lancet. 2004;364(9435):709-721.

33. Wang Z, Zheng $T$, Zhu Z, et al. Interferon gamma induction of pulmonary emphysema in the adult murine lung. J Exp Med. 2000;192(11): $1587-1600$

34. Trajkov D, Mirkovska-Stojkovikj J, Petlichkovski A, et al. Association of cytokine gene polymorphisms with chronic obstructive pulmonary disease in Macedonians. Iran J Allergy Asthma Immunol. 2009;8(1): $31-42$.

35. Anthonisen NR, Connett JE, Enright PL, Manfreda J; Lung Health Study Research Group, Hospitalizations and mortality in the Lung Health Study. Am J Respir Crit Care Med. 2002;166(3): 333-339.

36. Calverley PM, Anderson JA, Celli B, et al. Salmeterol and fluticasone propionate and survival in chronic obstructive pulmonary disease. N Engl J Med. 2007;356(8):775-789.

37. Sin DD, Wu L, Man SF. The relationship between reduced lung function and cardiovascular mortality: A population-based study and a systematic review of the literature. Chest. 2005;127(6):1952-1959.

38. McNicholas WT. Chronic obstructive pulmonary disease and obstructive sleep apnea: Overlaps in pathophysiology, systemic inflammation, and cardiovascular disease. Am J Respir Crit Care Med. 2009;180(8): $692-700$.

39. Vernooy JH, Küçükaycan M, Jacobs JA, et al. Local and systemic inflammation in patients with chronic obstructive pulmonary disease: Soluble tumor necrosis factor receptors are increased in sputum. Am J Respir Crit Care Med. 2002;166(9):1218-1224.
40. Yanbaeva DG, Dentener MA, Creutzberg EC, Wesseling G, Wouters EF. Systemic effects of smoking. Chest. 2007;131(5):1557-1566.

41. Brozyna S, Ahern J, Hodge G, et al. Chemotactic mediators of Th1 T-cell trafficking in smokers and COPD patients. COPD. 2009;6(1): 4-16.

42. MacCallum PK. Markers of hemostasis and systemic inflammation in heart disease and atherosclerosis in smokers. Proc Am Thorac Soc. 2005;2(1):34-43.

43. Mayosi BM, Avery PJ, Baker M, et al. Genotype at the $-174 \mathrm{G} / \mathrm{C}$ polymorphism of the interleukin- 6 gene is associated with common carotid artery intimal-medial thickness: family study and meta-analysis. Stroke. 2005;36(10):2215-2219.

44. Brull DJ, Montgomery HE, Sanders J, et al. Interleukin-6 gene $-174 \mathrm{~g}>\mathrm{c}$ and $-572 \mathrm{~g}>\mathrm{c}$ promoter polymorphisms are strong predictors of plasma interleukin-6 levels after coronary artery bypass surgery. Arterioscler Thromb Vasc Biol. 2001;21(9):1458-1463.

45. Podgoreanu MV, Schwinn DA. New paradigms in cardiovascular medicine: Emerging technologies and practices: Perioperative genomics. J Am Coll Cardiol. 2005;46(11):1965-1977.

46. Jenny NS, Tracy RP, Ogg MS, et al. In the elderly, interleukin-6 plasma levels and the $-174 \mathrm{G}>\mathrm{C}$ polymorphism are associated with the development of cardiovascular disease. Arterioscler Thromb Vasc Biol. 2002;22(12):2066-2071.

47. Walston JD, Fallin MD, Cushman M, et al. IL-6 gene variation is associated with IL-6 and C-reactive protein levels but not cardiovascular outcomes in the Cardiovascular Health Study. Hum Genet. 2007;122(5): 485-494.

48. Carty CL, Heagerty P, Heckbert SR, et al. Interaction between fibrinogen and IL-6 genetic variants and associations with cardiovascular disease risk in the Cardiovascular Health Study. Ann Hum Genet. 2010; 74(1):1-10.

49. Fried LP, Borhani NO, Enright P, et al. The Cardiovascular Health Study: Design and rationale. Ann Epidemiol. 1991;1(3):263-276.

50. van Eeden SF, Yeung A, Quinlam K, Hogg JC. Systemic response to ambient particulate matter: Relevance to chronic obstructive pulmonary disease. Proc Am Thorac Soc. 2005;2(1):61-67.

51. Helmersson J, Larsson A, Vessby B, Basu S. Active smoking and a history of smoking are associated with enhanced prostaglandin $\mathrm{F}$ (2alpha), interleukin-6 and F2-isoprostane formation in elderly men. Atherosclerosis. 2005;181(1):201-207.

52. Bermudez EA, Rifai N, Buring JE, Manson JE, Ridker PM. Relation between markers of systemic vascular inflammation and smoking in women. Am J Cardiol. 2002;89(9):1117-1119.

53. Woodward M, Rumley A, Tunstall-Pedoe H, Lowe GD. Associations of blood rheology and interleukin-6 with cardiovascular risk factors and prevalent cardiovascular disease. Br J Haematol. 1999;104(2): 246-257.

54. Kamath S, Lip GY. Fibrinogen: Biochemistry, epidemiology and determinants. QJM. 2003;96(10):711-729.

55. Ridker PM, Rifai N, Stampfer MJ, Hennekens CH. Plasma concentration of interleukin- 6 and the risk of future myocardial infarction among apparently healthy men. Circulation. 2000;101(15): 1767-1772.

56. Walter RE, Wilk JB, Larson MG, et al. Systemic inflammation and COPD: The Framingham Heart Study. Chest. 2008;133(1):19-25.

57. Tanaka G, Sandford AJ, Burkett K, et al. Tumour necrosis factor and lymphotoxin A polymorphisms and lung function in smokers. Eur Respir J. 2007;29(1):34-41.

58. Ardlie KG, Lunetta KL, Seielstad M. Testing for population subdivision and association in four case-control studies. Am J Hum Genet. 2002; 71(2):304-311.

59. Allison DB, Heo M, Schork NJ, Wong SL, Elston RC. Extreme selection strategies in gene mapping studies of oligogenic quantitative traits do not always increase power. Hum Hered. 1998;48(2):97-107.

60. Twardella D, Küpper-Nybelen J, Rothenbacher D, Hahmann H, Wüsten B, Brenner H. Short-term benefit of smoking cessation in patients with coronary heart disease: Estimates based on self-reported smoking data and serum cotinine measurements. Eur Heart J. 2004;25(23): 2101-2108. 
61. Critchley J, Capewell S. Smoking cessation for the secondary prevention of coronary heart disease. Cochrane Database Syst Rev. 2004;1; CD003041.
62. Gratziou C. Respiratory, cardiovascular and other physiological consequences of smoking cessation. Curr Med Res Opin. 2009;25(2): $535-545$.

International Journal of COPD

\section{Publish your work in this journal}

The International Journal of COPD is an international, peer-reviewed journal of therapeutics and pharmacology focusing on concise rapid reporting of clinical studies and reviews in COPD. Special focus is given to the pathophysiological processes underlying the disease, intervention programs, patient focused education, and self management protocols.

\section{Dovepress}

This journal is indexed on PubMed Central, MedLine and CAS. The manuscript management system is completely online and includes a very quick and fair peer-review system, which is all easy to use. Visit $\mathrm{http}: / /$ www.dovepress.com/testimonials.php to read real quotes from published authors.

Submit your manuscript here: http://www.dovepress.com/international-journal-of-copd-journal 